\title{
Numerical Aerodynamic Evaluation and Noise Investigation of a Bladeless Fan
}

\author{
M. Jafari, H. Afshin ${ }^{\dagger}$, B. Farhanieh and H. Bozorgasareh \\ Center of excellence in energy conversion, School of mechanical engineering, Sharif University of \\ technology, Tehran, Iran \\ $\dagger$ Corresponding Author Email: afshin@sharif.edu
}

(Received October 28, 2013; accepted January 26, 2014)

\begin{abstract}
Bladeless fan is a novel fan type that has no observable impeller, usually used for domestic applications. Numerical investigation of a Bladeless fan via Finite Volume Method was carried out in this study. The fan was placed in center of a $4 \times 2 \times 2 \mathrm{~m}$ room and 473 Eppler airfoil profile was used as cross section of the fan. Performance and noise level of the fan by solving continuity and momentum equations as well as noise equations of Broadband Noise Source (BNS) and Ffowcs Williams and Hawkings (FW-H) in both steady state and unsteady conditions were studied. Flow increase ratio of the fan was captured. Furthermore, BNS method could find outlet slit of the air as the main source of the noise generation. In order to validation of aeroacousticcode results, a simulation of noise for NACA 0012 airfoil via FW-H method was compared to experimental results and good agreement was obtained.
\end{abstract}

Keywords: Bladeless Fan, Computational Fluid Dynamics, Airfoil, Numerical Simulation, BNS \& FW-H Noise Formulations.

\section{NOMENCLATURE}

\begin{tabular}{|c|c|c|c|}
\hline$v$ & surface velocity & $p_{\text {ref }}$ & Reference pressure \\
\hline$l$ & length scale & & \\
\hline$a_{0}$ & velocity of sound & Greek letters & \\
\hline$x, y, z$ & cartesian coordinate & $\varepsilon$ & dissipation rate of turbulent kinetic energy \\
\hline$t$ & time & $\mu_{t}$ & turbulent viscosity \\
\hline$u$ & fluid velocity & $\rho$ & density \\
\hline$R 1, R 2$ & position of noise receiver & $\rho_{0}$ & unperturbed fluid density \\
\hline$p$ & static pressure & $\tau_{i j}$ & shear stress tensor \\
\hline$p^{\prime}$ & acoustic pressure & $\delta(f)$ & Dirac delta function \\
\hline$f$ & frequency & $\sigma_{k}, \sigma_{\varepsilon}$ & parameters of the standard $k-\varepsilon$ model \\
\hline$D$ & diameter & & \\
\hline$C_{1 \varepsilon}, C_{2 \varepsilon}, C_{\mu}$ & parameters of the standard $k-\varepsilon$ model & $\begin{array}{l}\text { Subscripts and } \\
\text { indices }\end{array}$ & \\
\hline$k$ & turbulent kinetic energy & $i, j$ & indices for cartesian tensor notation \\
\hline$p_{i j}$ & compressive stress tensor & $L$ & loading value \\
\hline$T_{i j}$ & lighthill's stress tensor & $n$ & normal vector \\
\hline$S$ & surface area & $r$ & component in radiation direction \\
\hline$H$ & heaviside function & $T$ & thickness term \\
\hline$r$ & distance between source and observer & $t$ & turbulence flow \\
\hline$r_{1 / 2}$ & $\begin{array}{l}\text { half-velocity width in the } \mathrm{r} \text { direction } \\
\text { based on the } \mathrm{u} \text {-velocity }\left[\mathrm{u}\left(\mathrm{r}_{1 / 2}\right)=\frac{1}{2} \mathrm{u}_{\mathrm{cl}}\right]\end{array}$ & $\begin{array}{l}c l \\
\text { in } \\
1,2,3\end{array}$ & $\begin{array}{l}\text { at the jet centerline } \\
\text { at inlet plane of jet } \\
\text { indices for directions } x, y, z\end{array}$ \\
\hline$M$ & Mach number & & \\
\hline
\end{tabular}




\section{INTRODUCTION}

Performance and noise are two important factors of fans that are studied more because of lots of fan applications in today's life including air ventilation and remove pollution. Typical fans include in sight big blades which may cause some defects such as be dislodged of their shaft after a long working time due to depreciation. A new category of fans was invented with no observable blade, called Bladeless or Air-multiplier fans, in 2009 (Gammack et al. 2009). This type of fan could multiply volume flow rate of its intake air by sucking air form backing of the fan, as a result of its specific geometry. Some other advantages are low depreciation, hidden blades and more safety. Moreover, multiply of intake flow rather than outlet flow and no danger for kids or pets are unique features of Bladeless fans. These specific characteristics have motivated many industrialists to start production of many types of this fan for various applications. Today, these fans in domestic scales are produced. Some geometric effective parameters for bladeless fans are thickness of airflow outlet slit, output angle of the flow relative to the fan axis and height of cross section of the fan.

Typical fans are divided into two types: axial and radial types, however Bladeless fans are completely different from typical fans in mechanism aspect. Although there is less studies about Bladeless fan in the literature, but many experimental and numerical studies can be found about performance of axial and radial fans. Chunxi et al. (2011) considered effect of enlarged impeller on performance of radial fan. They experimentally showedthat shaft power, total pressure rise, sound pressure level and flow rate increase, while the efficiency of fan decreases with larger blades. Lin and Huang (2002) examined performance of a radial fan for laptop cooling systems by numerical simulation and experimental tests. They used a NACA 4412 airfoil and evaluated the fan performance in various conditions. Hurault et al. (2012) considered performance of an axial fan by numerical and experimental methods, too and compared results of these various methods. There are many researches about geometric optimization of fans in literature. Mohaideen(2012) optimized a radial fan blade by finite element method. Finally, his optimization on the blade thickness via stress analysis by ANSYS commercial software could reduce the weight of the fan by $18.5 \%$.

Lighthill (1952) proposed the first equation for noise calculation in 1959. Lighthill's equation was only applicable for cases without an emerged body in the fluid. Curle (1955) expanded Lighthill's equation to solve this limitation. Afterwards, Ffowcs Williams and Hawkings (1969) extended the Lighthill-Curle's equation and introduced a standard approach for prediction of noise produced from rotating blades. Ffowcs Williams-Hawkings (FW-H) expanded the Lighthill's equation by combining mass and momentum equations. Nowadays, many people use FW-H method to evaluate noise of various turbomachines.

Many experimental or numerical investigations have been carried out in order to calculate the tonal noise of airfoils; numerical ones carried out most by FW-H method(Greschner et al. 2008and Mathy2008). Chong et al. (2012) measured produced noise of a NACA 0012 airfoil with angles of attack of $0^{\circ}, 1.4^{\circ}$, and $4.2^{\circ}$ for Reynolds numbers from $1 \times 10^{5}$ to $6 \times 10^{5}$ in a wind tunnel. They showed that pressure gradient increases on the airfoil pressure surface with increase of the angle of attack and it can lead to an instable noise for the airfoil. In addition, they found that many grooves at the back of the airfoil reduce the noise at high frequencies. Devenport et al. (2010) measured noise of NACA 0012, NACA 0015 and S831 airfoils in a turbulent flow, experimentally. They concluded that an airfoil with more thickness makes a lower noise level. Also, angle of attack has little effect on noise production of NACA 0012 and NACA 0015 airfoils. In recent years, Direct Numerical Simulation (DNS) method has also been used for prediction of airfoil noise. For example, Sandberg et al. (2011) simulated noise level of NACA 0012 airfoil via DNS method. Zhoua and Joseph (2007) calculated noise level of NACA 0012 and NACA 0024 airfoils in a uniform flow by numerical simulation. They observed only $6 \mathrm{~dB}$ difference between their numerical and experimental results.

Also, many researchers have studied noise of axial and radial fans by applying FW-H \& BNS formulations through 2D or 3D numerical simulations (Jiang et al. 2007). RamaKrishna et al. (2011) simulated noise level of a fan motor by FW-H model in FLUENT commercial software. They calculated aerodynamic noise of the fan and could reduce it by replacing straight radial blades with NACA 64-010 airfoil blades. Scheit et al. (2012) studied performance of a radial fan numerically and experimentally. Their results showed that choice of the blade wrap angle needs a tradeoffbetween aerodynamic efficiency and noise propagation. Wang et al. (2009) predicted noise of an axial fan by FW-H noise formulation and $k-\varepsilon$ turbulence model. Also, they simulated aerodynamic noise around the blades by BNS method. There are more numerical and experimental studies for prediction of fan noise (Hu et al. 2013 and Zhao et al. 2012).

As Bladeless fan was invented newly, its aerodynamic and aeroacoustic performances have not been studied in various working conditions. This type of fan is being produced in diameters of $30 \mathrm{~cm}$ or less for domestic applications, now. Geometric characteristics in the patent documentation are the only available information about it. In this study, aerodynamic and aeroacoustic performances of Bladeless fan in a $30 \mathrm{~cm}$ diameter are considered via a 3D simulation. Conservation of mass and momentum equations are solved for incompressible flow simulation of airflow. Although noise level of radial and axial fans has been achieved by numerical and experimental investigations already, noise level of Bladeless fan has not been studied carefully yet, except a not detailed statement that declares a range of 5060dB (CINO Power Machinery Co 2013). So, FW-H and BNS methods are used in both steady and unsteady forms in order to carry out noise calculations. Aeroacoustic performance of this fan is investigated for different intake volume flow rates in this research. First, BNS method is used to find source of the noise. Then, FW-H formulation is applied for calculation of the noise level. Also, a 2D NACA 0012 airfoil is simulated to validate results of the aeroacoustic code. Results of this airfoil are compared with experimental results of Brooks et al. (1989), too. 


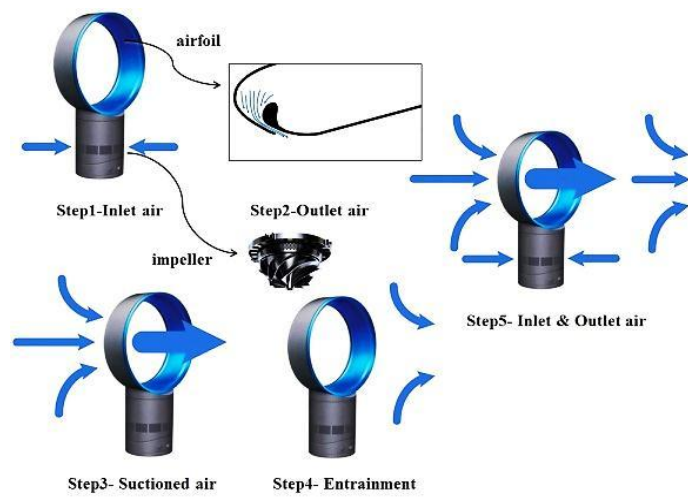

Fig. 1. Mechanism of entry and exit airflow from bladeless fan.

\section{BLADELESS FAN DESCRIPTION}

Fig. 1 shows an illustration of how Bladeless fan works. Five steps are demonstrated from the inlet flow to the outlet flow. First, suction of air is done by a radial impeller. Then, the air accelerates via moving through an annular zone with a cross section which looks like an airfoil profile. Finally, it exits from a ring shaped slit with a thickness of $1.3 \mathrm{~mm}$. High speed exit of the air leads to a pressure gradient between fan's back side and its front side according to Bernoulli's principle. This pressure gradient creates a suction of air from back side and pushes it forwards. Furthermore, the main output flow of the fan entrains the surrounding stationary air. Total of the inlet, suctioned,and the entrainedflowsreach to an overall amount of about 15 times of the inlet volume flow rate (Gammack et al. 2009 and Durdin 2008) at a distance of 3 times of the fan diameter far from the fan (Fig. 1).

\section{GOVERNING EQUATIONS}

\subsection{Aerodynamic Formulation}

Conservation of momentum and mass equations are solved numerically to consider the steady state and unsteady incompressible flow. In the general form, continuity equation in direction $x_{i}, i=1,2,3$ at time $t$ is given by:

$$
\frac{\partial \rho}{\partial t}+\frac{\partial}{\partial x_{i}}\left(\rho u_{i}\right)=0
$$

Where $u_{i}$ is velocity in $i$ direction and $\rho$ is density. Momentum equation is described as:

$\frac{\partial}{\partial t}\left(\rho u_{i}\right)+\frac{\partial}{\partial x_{i}}\left(\rho u_{i} u_{j}\right)=-\frac{\partial p}{\partial x_{i}}+\frac{\partial \tau_{i j}}{\partial x_{j}}$

where, $\tau_{i j}$ is stress tensor and $p$ denotes pressure. Standard $k-\varepsilon$ turbulence model is used to simulate turbulence flow which is a semi-empirical model proposed by Launder and Spalding (Launder and Spalding 1972). Equations of $k$ and $\varepsilon$ are as below:

$$
\begin{aligned}
& \frac{\partial}{\partial t}(\rho k)+\frac{\partial}{\partial x_{i}}\left(\rho u_{i} k\right)=\frac{\partial}{\partial x_{i}}\left[\left(\mu+\frac{\mu_{t}}{\sigma_{k}}\right) \frac{\partial k}{\partial x_{i}}\right] \\
& +G_{k}-\rho \varepsilon-Y_{M}+S_{k} \\
& \frac{\partial}{\partial t}(\rho \varepsilon)+\frac{\partial}{\partial x_{i}}\left(\rho u_{i} \varepsilon\right)=\frac{\partial}{\partial x_{i}}\left[\left(\mu+\frac{\mu_{t}}{\sigma_{\varepsilon}}\right) \frac{\partial \varepsilon}{\partial x_{i}}\right] \\
& +C_{1 \varepsilon} \frac{\varepsilon}{k} G_{k}-C_{2 \varepsilon} \rho \frac{\varepsilon^{2}}{k}+S_{\varepsilon}
\end{aligned}
$$

Moreover, turbulent (or eddy) viscosity is evaluated as:

$\mu_{t}=\rho C_{\mu} \frac{k^{2}}{\varepsilon}$

and

$G_{k}=\mu_{t}\left(\frac{\partial u_{j}}{\partial x_{i}}+\frac{\partial u_{i}}{\partial x_{j}}\right) \frac{\partial u_{j}}{\partial x_{i}}$

In Eqs. (3) and (4) $G_{k}$ represents production rate of turbulence kinetic energy. $Y_{M}$ represents the contribution of the fluctuating dilatation incompressible turbulence to the overall dissipation rate. $S_{k}$ and $S_{\varepsilon}$ are user-defined source terms. In these equations, the constant parameters are $C_{1 \varepsilon}=1.44, C_{2 \varepsilon}=1.92, C_{\mu}=0.09, \sigma_{k}=1.0$ and $\sigma_{\varepsilon}=1.3$.

In the present study, the time-dependent term of equations is discretized using a second order, implicit scheme. For discretization of the equations, central difference scheme for diffusion terms and second order upwind for convection terms is used. Minimum acceptable residual for all equations is $10^{-6}$. SIMPLE algorithm is employed for pressure and velocity coupling.

\subsection{Acoustic Computation}

\subsubsection{Broadband Noise Source (BNS) Method}

Broadband noise models often are used when acoustic details are not required. BNS aeroacoustic models can determine acoustic power per unit volume or surface. These models cannot provide any tonal noise information or noise spectra at a receiver location. They give just an approximate prediction of the propagated noise at the source of noise. Broadband models usually are used for certain problems and are not applicable in general. The noise level information at receiver location can be calculated using FW-H model which will be explained later. In this work, the BNS model is just used to find source of noise and determine the surface acoustic power contour.

\subsubsection{Ffowcs Williams-Hawkings (FW-H) Integral Methods}

Ffowcs Williams-Hawkings presented the following equation:

$$
\begin{aligned}
& \frac{1}{a^{2}{ }_{0}} \frac{\partial^{2} p^{\prime}}{\partial t^{2}}-\nabla^{2} p^{\prime}=\frac{\partial}{\partial t}\left\{\left[\rho 0 u_{n}+\rho\left(u_{n}-v_{n}\right)\right] \delta(f)\right\} \\
& -\frac{\partial}{\partial x_{i}}\left\{\left[p_{i j} n_{j}+\rho u_{i}\left(u_{n}-v_{n}\right)\right] \delta(f)\right\}+\frac{\partial^{2}}{\partial x_{i} \partial x_{j}}\left(T_{i j} H(f)\right)
\end{aligned}
$$

which, $v_{i}$ and $v_{n}$ are the surface velocity components in $x_{i}$ direction and normal to the surface. $u_{i}$ is fluid 
velocity in $x_{i}$ direction and $u_{n}$ is normal to the surface, $H(f)$ is Heaviside function, $\delta(f)$ is Dirac delta function and $p^{\prime}$ is sound pressure at far-field receiver location. In Eq. (7), the first term on the right-hand side is the influence of unsteady volume displacement of fluid by moving walls. Second term is due to interaction of flow with the rigid body and third term comes from the structure effect of flow. The first, second and third terms are named monopoles, dipoles and quadrupoles, respectively. Lighthill stress tensor, $T_{i j}$, and compressive stress tensor, $P_{i j}$, for a Stokesian fluid in Eq. (7) can be calculated as follow:

$T_{i j}=\rho u_{i} u_{j}+p_{i j}-a_{0}^{2}\left(\rho-\rho_{0}\right) \delta_{i j}$

and

$p_{i j}=p \delta_{i j}-\mu\left[\frac{\partial u_{i}}{\partial x_{j}}+\frac{\partial u_{j}}{\partial x_{i}}-\frac{2 \partial u_{k}}{3 \partial x_{k}} \delta_{i j}\right]$

Free-stream quantities are defined by the subscript 0 . Solution of Eq. (7) is obtained by free-space Green function $(\delta(g) / 4 \pi r)$. By Integrating Eq. (7), the first and the second terms lead to a surface integral but the third term leads to a volume integral. So, the complete solution consists of surface integrals and volume integrals. However, contribution of the volume integrals is negligible when the flow is low. According to the above, volume integrals are dropped in this work. Moreover, by neglecting the third term and using the Green's function (Eq.(7)) following integral form is achieved:

$$
\begin{aligned}
& p^{\prime}(\vec{x}, t)=p_{T}^{\prime}(\vec{x}, t)+p_{L}^{\prime}(\vec{x}, t) \\
& 4 \pi p_{T}^{\prime}(\vec{x}, t)=\int_{f}=0\left[\frac{\rho_{o}\left(\dot{U}_{n}+U_{\dot{n}}\right)}{r\left(1-M_{r}\right)^{2}}\right] d S \\
& +\int_{f}=0\left[\frac{\rho_{0} U_{n}\left(r \dot{M}_{r}+a_{0}\left(M_{r}-M^{2}\right)\right)}{r^{2}\left(1-M_{r}\right)^{3}}\right] d S \\
& 4 \pi p_{L}^{\prime}(\vec{x}, t)=\frac{1}{a_{0}} \int_{f}=0\left[\frac{\dot{L}_{r}}{r\left(1-M_{r}\right)^{2}}\right] d S \\
& +\int_{f=0}\left[\frac{L_{r}-L_{M}}{r^{2}\left(1-M_{r}\right)^{2}}\right] d S+\frac{1}{a_{0}} \int_{f}=0\left[\frac{L_{r}\left\{r \dot{M}_{r}+a_{0}\left(M_{r}-M^{2}\right)\right\}}{r^{2}\left(1-M_{r}\right)^{3}}\right] d S
\end{aligned}
$$

Where $\tau=t-\frac{r}{a_{0}}$ and

$U_{i}=v_{i}+\frac{\rho}{\rho_{0}}\left(u_{i}-v_{i}\right)$

$L_{i}=p_{i j} n_{j}+\rho u_{i}\left(u_{n}-v_{n}\right)$

This formulation is based on Farassat's(Brentner and Farassat 1998) solution of the FW-H equation.

\section{VALIDATION}

\subsection{Aerodynamic Validation}

For correction of the fan cross section that is similar to airfoil, aerodynamic coefficients of corrected airfoil and the original airfoil by inventor were compared together. So, validation of aerodynamic results is required. Hence, numerical results of drag and lift coefficient

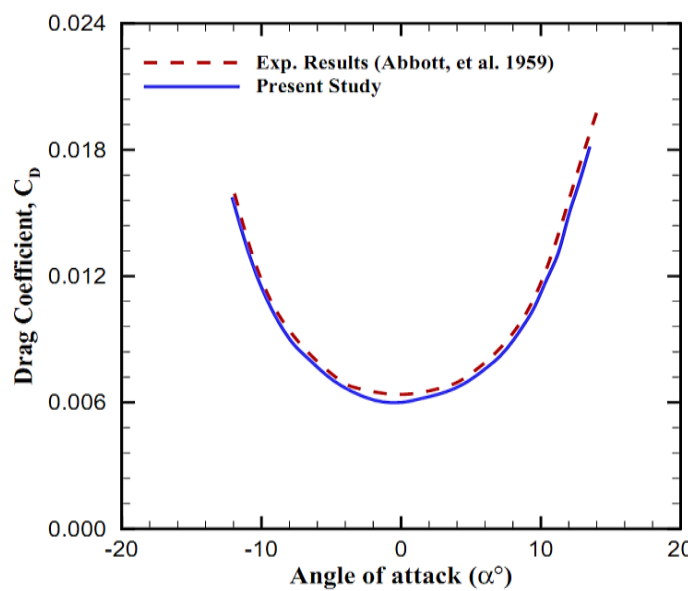

Fig. 2. Drag coefficient diagram via angle of attack at $\mathrm{Re}=3 \times 10^{6}$.

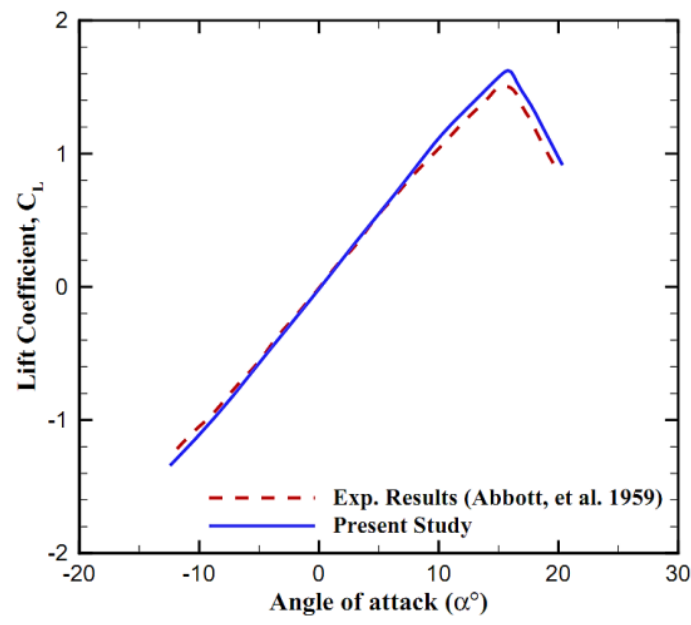

Fig. 3. Lift coefficient diagram via angle of attack at $\mathrm{Re}=3 \times 10^{6}$.

diagrams of NACA 0012 airfoil were compared with experimental data of Abbott et al. (Abbott and Von Doenhoff 1959). Many experimental and numerical studies have been carried out on various types of airfoils. Ghassemi and Kohansal (2013) studied flow field on a NACA4412 airfoil via boundary elementmethod. They compared their numerical and experimental results to validate and showed that this method can simulate the flow with wave pattern well. Belkheir et al. (2012) simulated 2D and 3D flow on a NACA0012 by Fluent software. They used $k-\varepsilon$ and SST turbulence models. In addition to comparison to experimental results, they compared results of these both turbulence models and concluded that for simulation of this phenomenonthe SST model results are closer to the experiment ones.

In our simulation, boundary condition of velocity inlet (Fig. 4) was introduced for inlet. Pressure outlet condition was set at the exit side with a relative pressure of zero. As standard k-e turbulence model was applied to the simulation in the present study, distance of the first next to wall cell from it was set to 0.001 meter, so $\mathrm{y}^{+}$for the first cell (45) is in the range of 30 to 300 and the results are more confident. The results have 


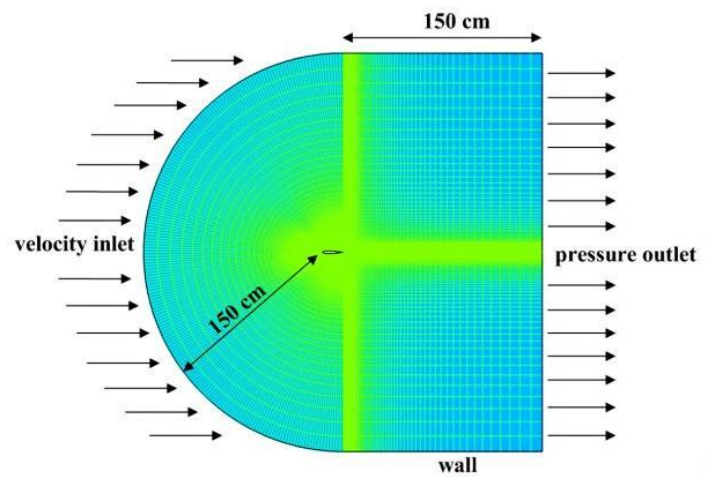

Fig. 4. Simulated geometry and boundary conditions for NACA 0012 airfoil.

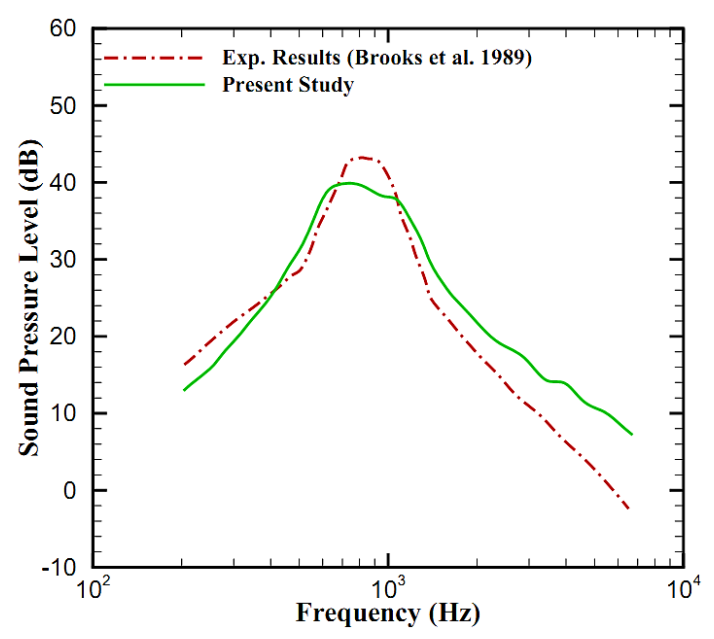

Fig. 5. Generated noise by NACA 0012 airfoil at $\operatorname{Re}=2 \times 10^{5}$.

been showed in Fig. 2 and Fig. 3, respectively. The diagrams were captured for Reynolds number of $3 \times 10^{6}$ for different angle of attacks. Both results showed a good agreement between numerical and experimental results.

\subsection{Noise Validation}

In this part, noise of NACA 0012 airfoil with zero angle of attack calculated in a 2D domain as validation of aeroacousticcode. Cord length of the airfoil was $0.15 \mathrm{~m}$ and the walls located 10 times the cord length far from the airfoil (Eleni et al. 2012). Boundary conditions, structured grid mesh and geometrical dimensions have been showed in Fig. 4. Results of this study and experimental data of Brooks et al. (1989) for NACA 0012 airfoil noise with Reynolds number of $2 \times 10^{5}$ have been compared in Fig. 5. The noise was measured with a sensor located at $1.25 \mathrm{~m}$ perpendicular to the trailing edge. Although numerical results did not follow experimental data exactly, their trend is the same as experimental data. Hence, FW-H model was found suitable for prediction of Bladeless fan noise.

\subsection{Validation of Fan Simulation}

There is no sufficient and detailed experimental data of Bladeless fan in the literature for validation. Bladeless

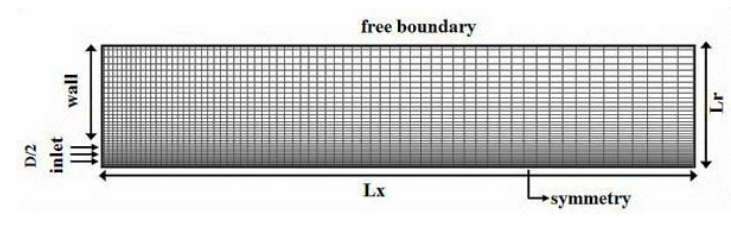

Fig. 6. Mesh and schematic of considered geometry and boundary conditions.

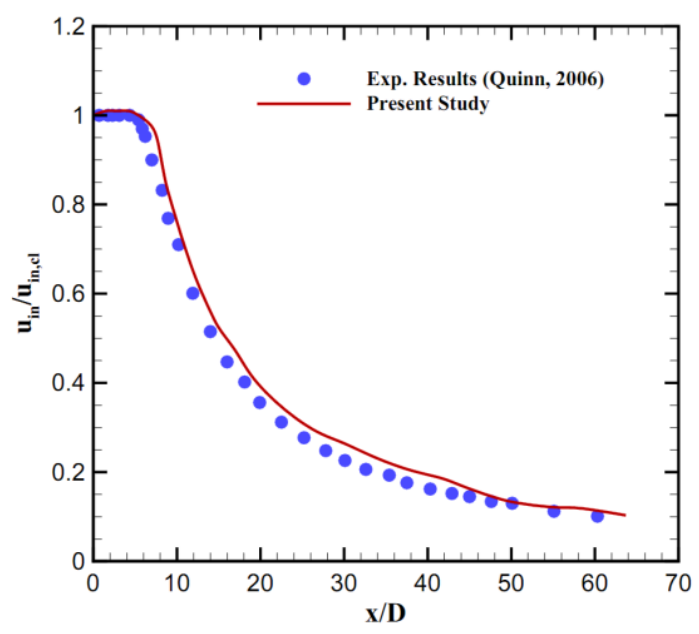

Fig. 7. Streamwise velocity decay along the jet centerline.

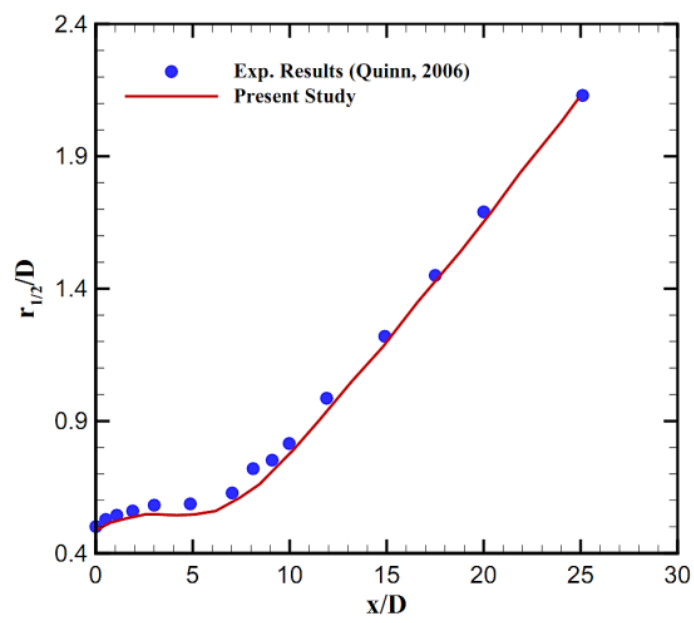

Fig. 8. Comparison between experimental and numerical results of spreading of jet.

fan in the exit part acts as a jet flow, so physics of both phenomena can be accounted about the same. Hence, experimental data of a circular jet (Quinn, 2006) was used to validate Bladeless fan simulation in this study. The mesh grid and boundary conditions have been shown in Fig.6. In order to reduce numerical costs, the jet was modeled in two-dimensional and axisymmetric. The domain dimensions were included 100 times of the jet diameter in length (Lx) and 20 times of it in width $(\mathrm{Lr})$. The $k-\varepsilon$ standard turbulence model was used for turbulence modeling. The inlet velocity was set to $60 \mathrm{~m} / \mathrm{s}$ uniformly and Reynolds number was $1.84 \times 10^{5}$. 
As it can be seen in Fig.5, streamwise velocity along centerline of the jet decreases. $u_{\text {in,cl }}$ represents the inlet velocity and $\mathrm{u}_{\mathrm{cl}}$ is the streamwise velocity at centerline of the jet. Also in Fig. 6, $r_{1 / 2}$ is jet half width that is defined as the radial distance from the centerline which the streamwise velocity equals to half of the centerline velocity at the same section. Comparison between numerical and experimental results in both above figures shows good agreement, therefore $k-\varepsilon$ model can simulate exit flow field of a circular jet with an acceptable accuracy.

\section{REFORM OF FAN'S CROSS SECTION}

In order to achieve a better performance, Eppler 473 airfoil profile was selected among standardized airfoils and evaluated as the fan's cross section, because it has a high curvature (good Coanda surface) and thus, a better suction of the air from back of the fan can be done. In addition, as it has a symmetric geometry and a flat upper surface, separation occurrence is less probable, so the output flow will be more uniform. Moreover the airfoil profile of Eppler 473 is suitable for lowReynolds numbers (Selig et al. 1995).Eppler airfoil and the airfoil used by inventor have been shown in Fig 9 and Fig. 10, respectively.

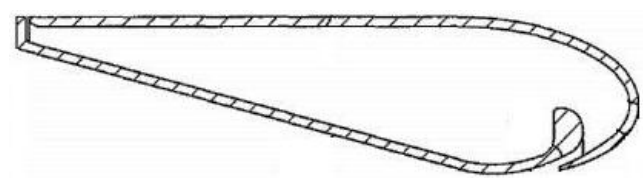

Fig. 9. Fan cross section profile mentioned in the inventor document.

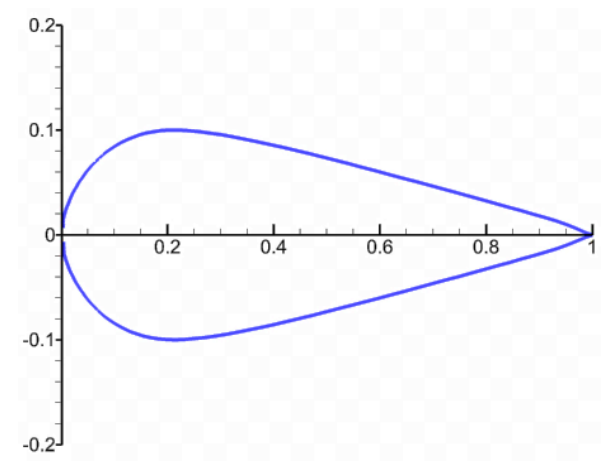

Fig. 10. Eppler 473 airfoil profile.

As Reynolds number for Bladeless fan is around $1 \times 10^{5}$, analysis of this study was carried out for this value. Fig. 11 and Fig. 12 show diagrams of lift coefficient and lift to drag ratio, respectively via angle of attack for both airfoils. As it can be seen, Eppler 473 airfoil has more lift coefficient for angles of attack between 10 to 17 degrees (angle of attack rang for fan cross section). Also, it delivers more lift to drag ratio and subsequently, more outlet volume flow rate can be delivered. So, it seems that Eppler 473 airfoil is more suitable for cross section of Bladeless fan.

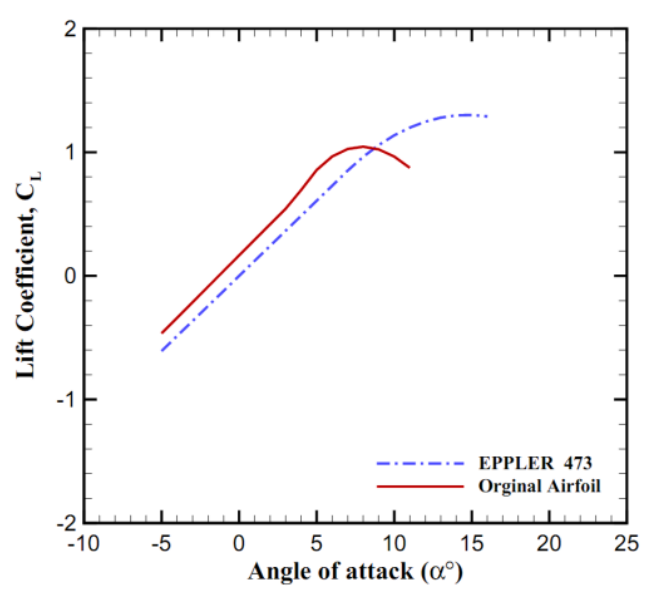

Fig. 11. Lift coefficient comparison for the both airfoils.

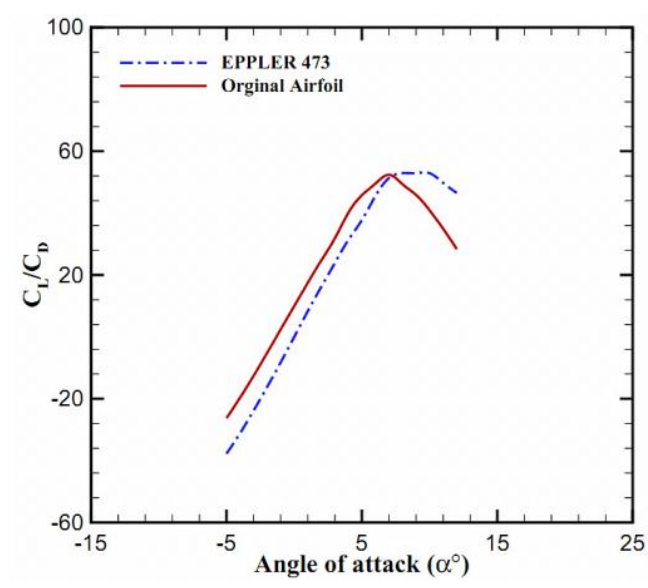

Fig. 12. Lift to drag coefficient ratio comparison for the both airfoils.

\section{Simulation Method}

A $30 \mathrm{~cm}$ in diameter Bladeless fan was modeled in a $4 \times 2 \times 2 \mathrm{~m}$ room (Fig. 13). Concentration was on geometrical characteristics of the top section in this study, so no motor and radial impeller were simulated here. Instead, the adequate mass flow inlet boundary condition was set to the inlet duct in each simulation. As it can be seen in Fig. 13, the air was inputted to the fan from a cylindrical section with a diameter of $9 \mathrm{~cm}$. Boundary condition of no slip was introduced for the floor and wall of the fan which have been colored in green in the figure. Mass flow rate boundary condition was set to the fan inlet that can be seen in Fig. 13 . Constant zero relative pressure was defined for other sides of the room which has been marked with free boundary in Fig. 13.

Cross section of designed airfoil (Eppler 473) for the fan and its dimensions were showed in Fig. 14 as well as the angles. As mentioned previously, the computational domain includes the internal fan zone and surrounding room. Airflow enters the fan through the inlet and then will discharge to the surrounding room through the outlet and suctions the air at the back and around of the fan.Two noisereceivers were located in a distance of $1 \mathrm{~m}$ far from the fan, in both sides (Fig. 15). 


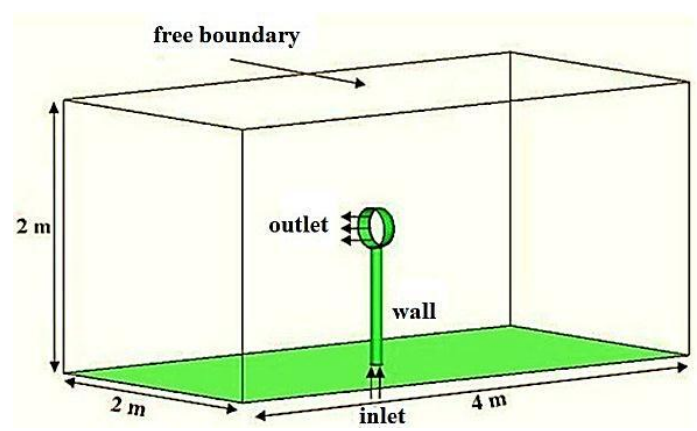

Fig. 13. An illustration of the fan modeling and boundary conditions.

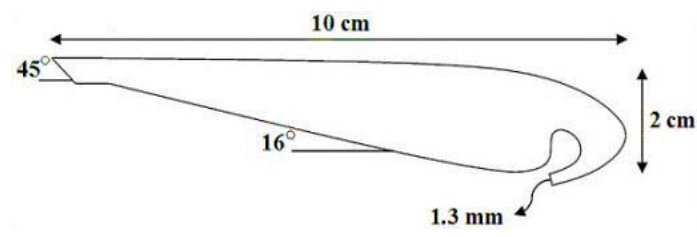

Fig. 14. Geometrical dimensions of designed cross section (Eppler 473 airfoil).

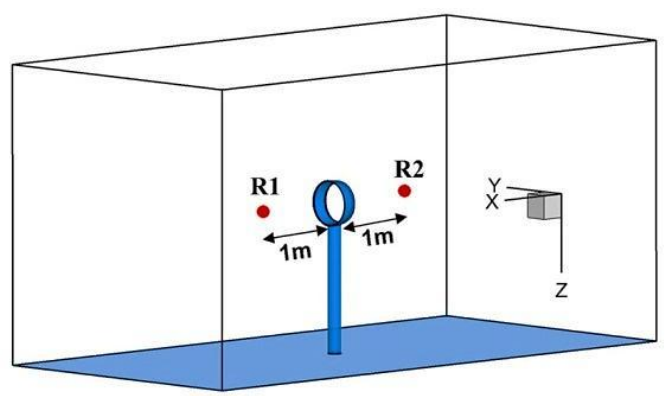

Fig. 15. Location of two noise sensors.

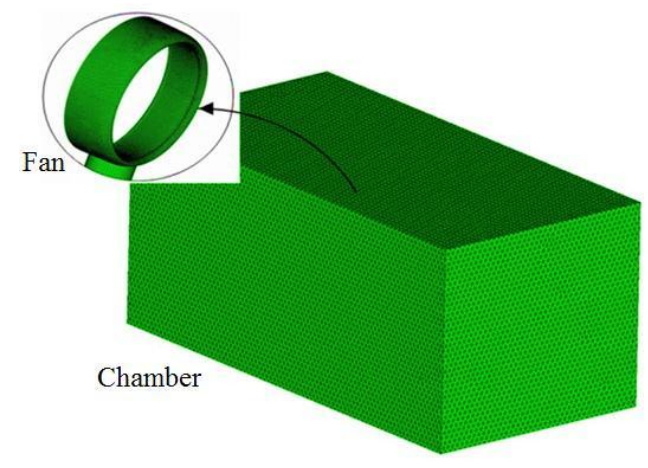

Fig. 16. Mesh generation for Bladeless fan and surrounding room.

\subsection{Grid Sensivity}

Unstructured mesh was used for simulation of the fan and the surrounding room that has been shown in Fig. 16.

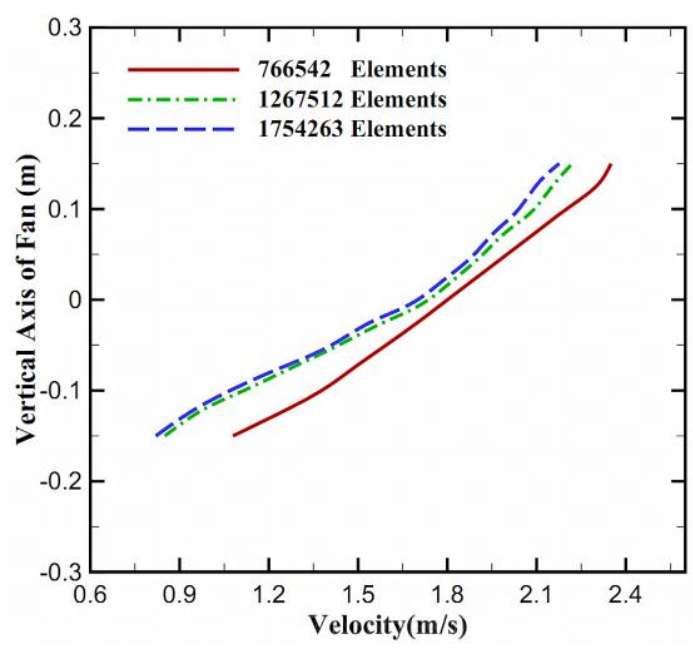

Fig. 17. Measured velocity profiles at a distance of $50 \mathrm{~cm}$ in front of the fan.

In order to find less suitable number of cells, three meshes were generated. Velocity profile of air at $50 \mathrm{~cm}$ away from the front end was captured for each mesh and all compared in Fig. 17. It can be concluded that the grid with 1267512 cells is sufficient and hence,this grid was used for the simulations in this study.

\section{RESUlts AND DISCUSSION}

\subsection{Aerodynamic}

Outlet flow increase compared to the inlet one is one of the characteristics of Bladeless fan. So, outlet volume flow rate of the fan was measured in a distance of 3 times fan diameter away from the front edge. Fig. 18 shows the outlet volume flow rate via the inlet volume flow rate. As it can be seen, the curve is straight with a constant slope (flow increase ratio) and equal to about 21. In invention documentary (Gammack et al. 2009), this value was found 15 . According to the above, it can be concluded that flow increase ratio is $40 \%$ higher for Eppler 473 airfoil rather than the inventor airfoil.

Pathlinesat surrounding area of the fan at symmetric surface have been shown in Fig.19. It is seen that outlet flow is highly uniform in comparison to typical fans; it is another specification of this type of fan.

To better understanding of flow field, velocity vectors and contours were captured in Fig. 20 and Fig. 21, respectively. Velocity contours show that the upper region has reached to a higher velocity rather than the lower one. This is due to air acceleration during passage through the annular section. As it was seen in Fig. 17, velocity profile in front of the fan is rather linear. However, this fact has low effect on the fan performance and the outlet flow is uniform already.

\subsection{Aeroacoustic}

BNS model was used for noise source detection in this study since it produces good information with a little calculation time. Inlet volume flow rate prescribed to the model was $30 \mathrm{~L} / \mathrm{s}$ in a steady state condition. Surface acoustic power contour for Bladeless fan has been 


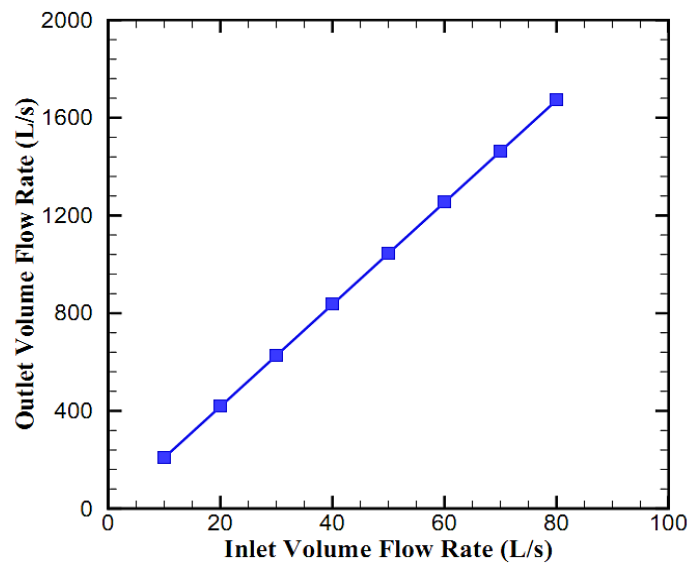

Fig. 18. Diagram of flow increase ratio for the fan with $1.3 \mathrm{~mm}$ outlet slit and $30 \mathrm{~cm}$ diameter.

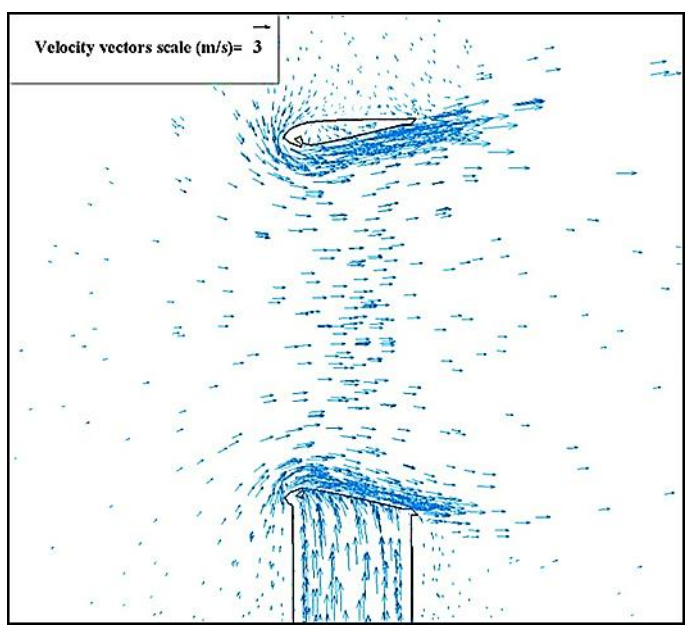

Fig. 20. Velocity vector contour at the symmetry plane.

shown in Fig 22. It obviously shows that the output slit is main source of noise. The reason is that high pressure and vorticity gradients take place at this slit. For calculation of sound pressure level (SPL), the output slit was prescribed as the noise source to be used in FW-H analysis.

Two noise receivers were placed in front and back of the fan, at a distance of $1 \mathrm{~m}$ [2]. SPL data in front of the fan was calculated (fig 23) by FFT algorithm and the following equation:

$$
S P L=10 \log \left(p / p_{\text {ref }}\right)^{2}
$$

Where $P_{r e f}=20 \times 10^{-6} \mathrm{pa}$. The diagram shows that SPL reduces with increase of frequency, but with a low rate of reduction, because no impeller has been modeled.

For a better understand of aeroacoustic performance of the fan, OASPL diagram for different inlet volume flow rates was shown in Fig. 24. It shows that the noise level in front and back of the fan are the same. Following correlation can approximate OASPL results:

$\operatorname{OASPL}(d B)=24.497 \times I V F(L / s)^{0.2323}$

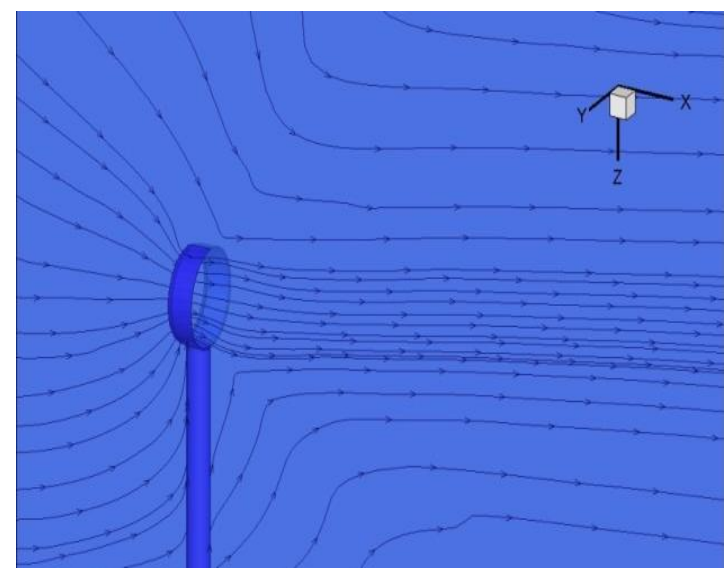

Fig. 19. Pathlines at the symmetry plane.

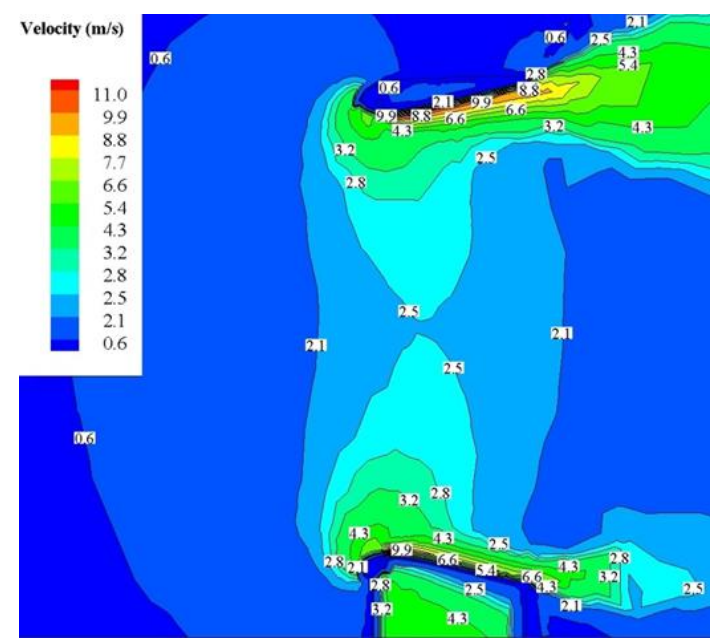

Fig. 21. Velocity contour at symmetry plane.

Where IVF is inlet volume flow rate to the fan in L/s. OASPL results show that with volume flow rate increase, soundpressure level increases. So, for application of this fan in a long period of time, it is suggested that IVF be less than $80 \mathrm{~L} / \mathrm{s}$ which produces a noise less than 70dB (Kujawa and Liberman 2009 and NIOSH 1998).

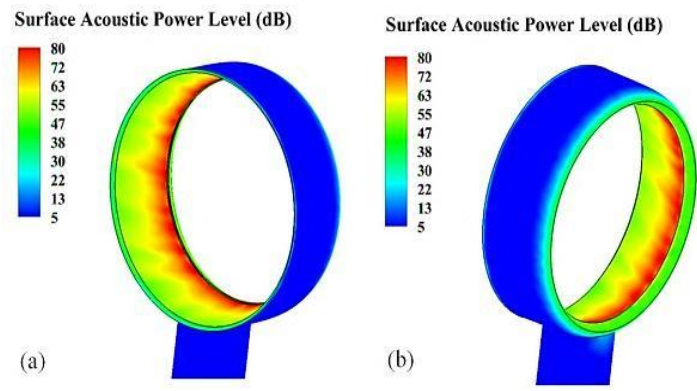

Fig. 22. Sound power contour at (a) front side (b) back side of the fan. 


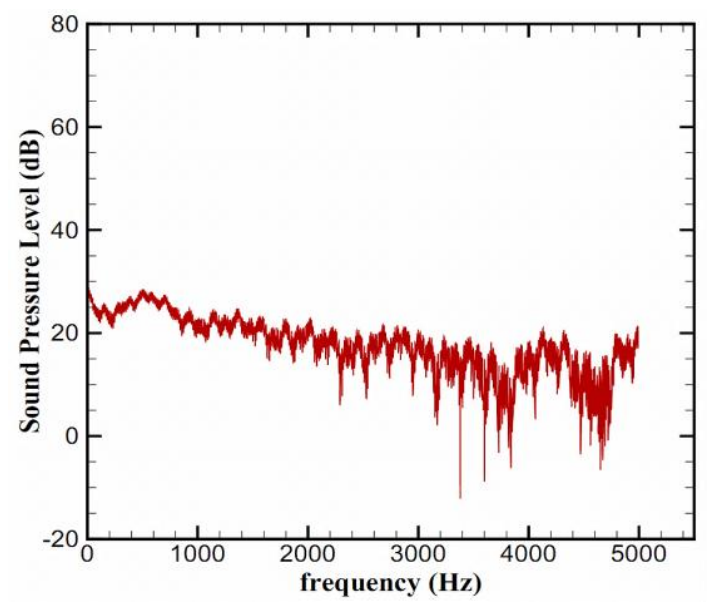

Fig. 23. SPL diagram at $1 \mathrm{~m}$ in front of the fan for inlet flow rate of $30 \mathrm{~L} / \mathrm{s}$.

\section{Conclusion}

In this study, aerodynamic and aeroacoustic performance of a Bladeless fan with a $30 \mathrm{~cm}$ diameter was investigated by numerical simulation. Results showed that with increase of the inlet volume flow rate, the outlet volume flow rate increases linearly. The ratio of outlet volume flow rate to the inlet one was 21 . This amount of volume flow rate increase can be known as a unique characteristic of this type of fan rather than the other types. Another result was that the velocity profile in front of the fan is linear; in front of the fan, outlet velocity at the top is more than the below. However, since there is no significant difference, the outlet flow can be evaluated about uniform, already. In order to carry out a noise investigation, BNS method was used to find the source of noise and FW-H method was applied to measure the noise level. The aeroacoustic

\section{REFERENCES}

Abbott, I. H., \& Von Doenhoff, A. E. (1959). Theory of wing sections: including a summary of airfoil data. Dover publications.

Belkheir, N., Dizene, R., Khelladi, S., (2012). A Numerical Simulation of Turbulence Flow Around a Blade Profile of HAWT Rotor in Moving Pulse. Journal of Applied Fluid Mechanics, 5(1), 1-9.

Brentner, K. S., Farassat, F., (1998). Analytical Comparison of the Acoustic Analogy and Kirchhoff Formulation for Moving Surfaces. AIAA journal, 36(8), 1379-1386.

Brooks, T. F., Pope, D. S., Marcolini, M. A. (1989). Airfoil self-noise and prediction.NASA Reference Publication. Vol. 1218.

Chong, T. P., Joseph, P. F., Kingan, M. J. (2012). An Investigation of Airfoil Tonal Noise at Different Reynolds Numbers and Angles of Attack. Applied

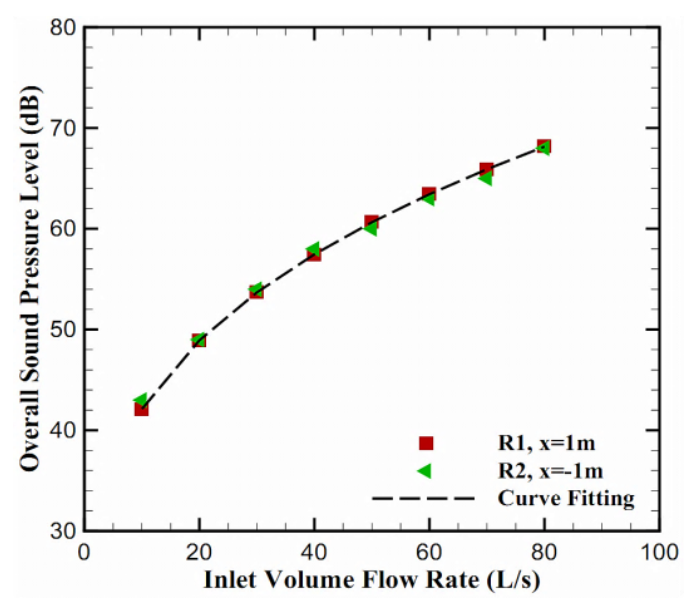

Fig. 24. OASPL diagram for $\mathrm{R} 1 \& \mathrm{R} 2$ receivers.

results showed that the more inlet volume flow rate, the more produced noise. Although increase of the inlet flow rate can increase the outlet one linearly, but regarding the produced noise, domestic application of this fan requires a compromise between the inlet flow rate and the produced noise, becausegenerated noise can be harmful for human health at high amounts of the inlet flow rate. This study showed that the inlet volume flow rate for this fan with $30 \mathrm{~cm}$ diameter and Eppler 473 profile should not bemore than $80 \mathrm{~L} / \mathrm{s}$, because it can be harmful for human health.

\section{ACKNOWLEDGEMENTS}

The authors gratefully acknowledge the Center of Excellence in Energy Conversion, School of Mechanical Engineering.

Acoustics.74,38- 48

Chunxi, L., Ling, W. S., Yakui, J., (2011). The Performance of a Centrifugal Fan with Enlarged Impeller. Energy Conversion and Management, 52(8), 2902-2910.

Curle, N., (1955). The Influence of Solid Boundaries Upon Aerodynamic Sound. Proceedings of the Royal Society of London. Series A. Mathematical and Physical Sciences, 231(1187), 505-514.

Devenport, W. J., Staubs, J. K., Glegg, S. A., (2010). Sound Radiation From Real Airfoils in Turbulence. Journal of Sound and Vibration, 329(17), 3470-3483.

Durdin, J., (2008). Inventing the 21st Century': An Exhibition at the British Library. World Patent Information. 33(2): p. 190-191.

Eleni, D. C., Athanasios, T. I., Dionissios, M. P., (2012). Evaluation of the Turbulence Models for the Simulation of the Flow over a National 
Advisory Committee for Aeronautics (NACA) 0012 Airfoil. Journal of Mechanical Engineering Research, 4(3), 100-111.

Gammack, P.D., Nicolas .F, Simmonds, K.J., (2009). Bladeless Fan, in Patent Application Publication. US 2009/0060710Al. United States.

General Catalogs of Bladeless fan by CINO Power Machinery Co., Ltd. (2003) (http://www.bladelessfan.so).

Ghassemi, H., Kohansal, A. R., (2013). Wave Generated by the NACA4412 Hydrofoil Near Free Surface. Journal of Applied Fluid Mechanics, 6(1), 1-6.

Greschner B, Thiele F, Jacob M, Casalino D (2008) Prediction of Sound Generated by a Rod-Airfoil Configuration Using EASM DES and the Generalised Lighthill/FW-H Analogy. Comput Fluids. 37:402-413.

Hu, B. B., OuYang, H., Wu, Y. D., Jin, G. Y., Qiang, X. Q., Du, Z. H., (2013). Numerical Prediction of the Interaction Noise Radiated From an Axial Fan. Applied Acoustics, 74(4), 544-552.

Hurault, J., Kouidri, S., Bakir, F., (2012). Experimental Investigations on the Wall Pressure Measurement on the Blade of Axial flow Fans. Experimental Thermal and Fluid Science, 40, 29-37.

Jiang, C. L., Chen, J. P., Chen, Z. J., Tian, J., OuYang, H., Du, Z. H., (2007). Experimental and Numerical Study on Aeroacoustic Sound of Axial Flow Fan in Room Air Conditioner. Applied Acoustics. 68(4), 458-472.

Kujawa, S.G., Liberman, M.C., (2009). Adding Insult to Injury: Cochlear Nerve Degeneration after "Temporary" Noise-Induced Hearing Loss. Journal of Neuroscience, 29(45): p. 14077-14085.

Launder, B. E., Spalding, D. B., (1972). Mathematical Models of Turbulence. Academic Press ,London.

Lighthill, M. J., (1952). On sound generated aerodynamically: I General theory, Proc. Roy. Soc. Lond. Ser. A Math. Phys. Sci. 211 564-587.

Lin, S. C., Huang, C. L., (2002). An Integrated Experimental and Numerical Study of ForwardCurved Centrifugal Fan. Experimental Thermal and Fluid Science, 26(5), 421-434.

Mathey, F., (2008). Aerodynamic Noise Simulation of the Flow Past an Airfoil Trailing-Edge Using a Hybrid Zonal RANS-LES. Computers \& Fluids, 37(7), 836-843.

Mohaideen, M. M., (2012). Optimization of Backward
Curved Aerofoil Radial Fan Impeller Using Finite Element Modelling. Procedia Engineering, 38, 1592-1598.

Quinn, W. R. (2006). Upstream Nozzle Shaping Effects on Near Field Flow in Round Turbulent Free Jets. European Journal of Mechanics-B/Fluids, 25(3), 279-301.

Rama Krishna, S., Rama Krishna, A., Ramji, K., (2011). Reduction of Motor Fan Noise Using CFD and CAA Simulations. Applied Acoustics, 72(12), 982-992.

Sandberg, R. D., Jones, L. E., (2011). Direct Numerical Simulations of Low Reynolds Number Flow over Airfoils with Trailing-Edge Serrations. Journal of Sound and Vibration, 330(16), 3818-3831.

Scheit, C., Karic, B., Becker, S., (2012). Effect of Blade Wrap Angle on Efficiency and Noise of Small Radial Fan Impellers-A Computational and Experimental Study. Journal of Sound and Vibration, 331(5), 996-1010.

Selig, M. S., Lyon, C. A., Giguere, P., Ninham, C., Guglielmo, J. J. (1995). Summary of Low-Speed Airfoil Data (Vol. 1). Virginia Beach, VA: SoarTech Publications.292 pp.

U.S. National Institute for Occupational Safety and Health (NIOSH)., (1998). Criteria for a Recommended Standard: Occupational Noise Exposure: Revised Criteria 1998. US Department of Health and Human Services Publication Number, p. 98-126.

Wang, Q., Hess, M., Matyschok, B., Pelz, P., (2009), Simulation of the Flow and Acoustic Field of a Fan. The $14^{\text {th }}$ International Conference on Fluid Flow TechnologiesBudapest, Hungary, September 9-12.

Williams, J. F., Hawkings, D. L., (1969). Sound Generation by Turbulence and Surfaces in Arbitrary Motion. Philosophical Transactions of the Royal Society of London. Series A, Mathematical and Physical Sciences, 264(1151), 321-342.

Zhao, X., Sun, J., Zhang, Z., (2012). Prediction and Measurement of Axial Flow Fan Aerodynamic and Aeroacoustic Performance in a Split-Type AirConditioner Outdoor Unit. International Journal of Refrigeration. 36(3): p. 1098-1108.

Zhou, Q., Joseph, P., (2007). A Frequency Domain Numerical Method for Airfoil Broadband SelfNoise Prediction. Journal of Sound and Vibration, 299(3), 504-519. 